\title{
SERVE EFFICIENCY DEVELOPMENT AT WIMBLEDON BETWEEN 2002 AND 2015: A LONGITUDINAL APPROACH TO IMPACT TOMORROW'S TENNIS PRACTICE
}

original paper

(c) University School of Physical Education in Wroclaw

DOI: https://doi.org/10.5114/hm.2020.88155

\section{RALPH GRAMBOW ${ }^{1}$, CRAIG O’SHANNESSY ${ }^{2}$, PHILIPP BORN ${ }^{1}$, DOMINIK MEFFERT ${ }^{1}$, TOBIAS VOGT ${ }^{1,3}$}

${ }^{1}$ Institute for Professional Sport Education and Sport Qualifications, German Sport University Cologne, Cologne, Germany

${ }^{2}$ Brain Game Tennis, Austin, USA

${ }^{3}$ Faculty of Sport Science, Waseda University, Tokorozawa, Saitama, Japan

\section{ABSTRACT}

Purpose. Good serving is crucial to succeed in men's world class tennis; however, both chronological and skill-related service game development remain to be elucidated. The study aimed to systematically analyse the development of serving behaviour and serve efficiency in world class men's tennis over a period of 14 years.

Methods. Historical data collected from all matches at the Wimbledon Championship between 2002 and 2015 (matches: $n=1772$; service games: $n=63,838$; serves: $n=401,527$ ) were included for analyses. The analyses focused on 2 comparisons, serve efficiency development over time and possible differences within the world class, i.e. 1st tournament week results (matches: $n=1563$; service games: $n=55$,989; serves: $n=352,748$ ) and 2nd tournament week results (matches: $n=209$; service games: $n=7849$; serves: $n=48,779$ ).

Results. An increase was observed of the percentages for service games won $(p<0.01)$, aces served $(p<0.01)$, and $1^{\text {st }}$ and $2^{\text {nd }}$ serve points won $(p<0.01)$, whereas double faults $(p<0.05)$ and serve and volley points played $(p<0.01)$ decreased over time. Direct comparisons of the $1^{\text {st }}$ and $2^{\text {nd }}$ tournament week show advantages in favour of the $2^{\text {nd }}$ tournament week. Players competing in the $2^{\text {nd }}$ tournament week won higher percentages of service games $(p<0.01)$ and points on the $1^{\text {st }}$ $(p<0.01)$ and $2^{\text {nd }}$ serve $(p<0.05)$, and served more aces $(p<0.05)$ but fewer double faults $(p<0.05)$.

Conclusions. With a particular impact on the $2^{\text {nd }}$ tournament week, the findings indicate increased serve efficiency in men's world class grass court tennis from 2002 to 2015, which may imply altered practice patterns in tomorrow's training and coaching. Key words: world class men’s tennis, service game, match strategy, training, coaching

\section{Introduction}

Match statistics are more and more used by players and coaches to analyse, improve, and develop their game. Statistics are applied to analyse matches to eventually implement and transfer the gained knowledge from research into practice as well as into match preparation. To feed research that allows for a knowledge transfer and to develop a tennis practice that improves the game and eventually turns losing into winning players, numerous tennis-specific parameters are recorded for public availability by the Association of Tennis Professionals (ATP) and their tournaments.
Based on this, several studies have discussed advanced statistics to show and explain a players' success [1-3]. Herein, the importance of the return, the opening shots and, most of all, the serve and precisely its efficiency are well accepted to impact the outcome of a modern tennis match [4-8].

A longitudinal approach, which not only contains a large number of analysed matches but also compares a large period of time and furthermore separates the world class even more, might identify primary indicators for being very successful and, thus, winning matches.

Correspondence address: Ralph Grambow, Institute for Professional Sport Education and Sport Qualifications, German Sport University Cologne, Am Sportpark Müngersdorf 6, 50933 Köln, Germany, e-mail: r.grambow@dshs-koeln.de

Received: February 20, 2019

Accepted for publication: August 23, 2019

Citation: Grambow R, O’Shannessy C, Born P, Meffert D, Vogt T. Serve efficiency development at wimbledon between 2002 and 2015: a longitudinal approach to impact tomorrow's tennis practice. Hum Mov. 2020;21(1):65-72; doi: https://doi. $\operatorname{org} / 10.5114 / \mathrm{hm} .2020 .88155$. 
R. Grambow, C. O’Shannessy, P. Born, D. Meffert, T. Vogt, Serve efficiency development in tennis

The most important tennis tournaments, the socalled Grand Slam tournaments (Australian Open, French Open, Wimbledon, US Open), have a special role for several reasons. A total of 128 players compete at a Grand Slam tournament; with this, Grand Slam tournaments comprise the largest draw of all professional tennis tournaments. In order to win the championship, players need to win 7 consecutive rounds. Grand Slams are also played with a best of 5 modus, which means that in order to win a match, the player has to win 3 sets (in men's tennis). In no other tournament is it possible to win so many ranking points (e.g. 2000 ATP points) and receive such a great amount of price money (e.g. £2,250,000 at Wimbledon 2018). Therefore, Grand Slams are most difficult to win, which can be underlined by the small number of different Grand Slam winners over the past years compared with the number of different ATP-tournament winners (e.g., in 2003-2017, Grand Slam: 12; ATP 1000: 27; ATP 500: 63). Following this line of argumentation, a focus of a longitudinal approach on a Grand Slam tournament becomes reasonable. The 4 majors are played on different surfaces: the French Open on clay, the Australian and US Open on hardcourt, and Wimbledon on grass.

The present study focused on one particular tournament which is eventually known as the most famous and traditional tournament in tennis, Wimbledon. Winning this tournament is the highest possible reputation for professional tennis players. Although there are only a few grass court tournaments in the yearly professional tennis calendar, compared with the number of clay court and hardcourt tournaments, the above stated importance and reputation of the tournament legitimates a longitudinal approach focusing on grass court only.

There are several studies and even more coach's opinions stating the significance of the playing surface with regard to the results of an analytic statistical approach. These opinions may be controversial, as some see the court surface as a main indicator influencing the match outcome and game style [9], whereas others, more recently, recognize no effects of the court surface on the match outcome [10] or the rally length, for example $[11,12]$.

Wimbledon is the only Grand Slam tournament on grass court, which is known as the fastest surface played at this stage. Considering different opinions about the effects of the play surface, Knight and O’Donoghue [13] proved Wimbledon to be serve-beneficial. Hughes and Clarke [14] and O'Donoghue and Brown [6] showed serving was more important at Wimbledon than at the Australian Open. With the present study focusing on serve efficiency, analysing Wimbledon results is highly compatible.

The study aimed to prove increased service game efficiency over a period of 14 years (2002-2015) and, furthermore, find differences regarding the service game parameters within the men's tennis world class, by, for the first time, comparing the $1^{\text {st }}$ and $2^{\text {nd }}$ tournament week totals of men's Grand Slam tennis, which may serve the understanding of the importance of serve efficiency to win a Grand Slam tournament.

\section{Material and methods}

Longitudinal data from the Gentlemen's Wimbledon Championship 2002-2015 were collected in collaboration with Brain Game Tennis and in compliance with the German Sport University's Ethic Committee from the Wimbledon Information System, presented by IBM. The data include historical numbers for service parameters, such as aces, double faults, serve percentages, and game patterns, like serve and volley. The examined period contains a total of 1772 matches, 63,838 service games, 401,527 serves, 38,173 aces, and 14,420 double faults, which were considered for analyses.

The data analyses in this study focused on 2 main comparisons. The first one concerned the development and changes of the serve efficiency over time, in this case, from 2002 to 2015.

Choosing 2002 as the starting year for this longitudinal research seemed to be appropriate because Wimbledon organizers decided to rebuild all grass courts following the 2001 championships. The new courts were built out of $100 \%$ perennial rye grass, compared with old courts being a split of 70-30 rye grass and creeping red fescue. Furthermore, the International Tennis Federation introduced new balls in 2002, which would play faster or slower depending on the surface.

For the second focus, the examined world class of tennis players was further separated into the $1^{\text {st }}$ and $2^{\text {nd }}$ tournament week, in order to find possible differences within the world class and the even more successful world class (i.e. elite players) over a period of 14 years. Earlier studies analysed a smaller samples, such as semi-finals to the final or the whole tournament or combined different Grand Slam tournaments [4, 7, 15-17]. To the knowledge of the authors, particularly for the second part of the analyses, there are no published data that would cover such a long period.

For the comparison over time, the following details, which are widely accepted as valid measures of serve 
efficiency [18, 19], were compiled into spreadsheets for each of the 14 analysed years for all 7 played rounds:

- the number of service games won by all players (i.e., serve success);

- the number of the $1^{\text {st }}$ and $2^{\text {nd }}$ serves won by all players (i.e., serve success);

- the number of aces and double faults served by all players (i.e., serve performance);

- the number of points when serve and volley was played and the number of points when serve and volley was won by all players (i.e., serve strategy).

Serve efficiency parameters were categorized in 3 different groups: serve success, serve performance, and serve strategy. The first category, serve success, contains the parameters of service games won, the $1^{\text {st }}$ serve points won, and the $2^{\text {nd }}$ serve points won, since they show how successful a player was while serving, covering all different types of possibilities of how to win a point as a server (e.g. service winners, multiple shot rallies, etc.). The second category, serve performance, contains all served aces and double faults, being the sole parameters that only include the serve and no other shot by the server or the opponent. The third category, serve strategy, refers to all serve and volley points played and serve and volley points won, focusing on the special strategy of coming to the net directly with the serve.

For the $1^{\text {st }}$ and $2^{\text {nd }}$ tournament week, comparison data were collected separately and divided for rounds 1-3 into the $1^{\text {st }}$ tournament week spreadsheet and rounds from 4 to the final into the $2^{\text {nd }}$ tournament week spreadsheet. The $1^{\text {st }}$ tournament week data set examines 1563 matches, 55,989 service games, 352,748 serves, 33,111 aces, and 12,993 double faults, whereas the $2^{\text {nd }}$ tournament week data set contains a total of 209 matches, 7849 service games, 48,779 serves, 5062 aces, and 1427 double faults.

Statistical procedures were performed by using Statistica 7.1 (StatSoft Inc., Tulsa, USA) as well as Excel 2016 (Microsoft Corp., Redmond, USA).

The comparison over time was performed by Spearman's rank correlations analyses, with the correlations interpreted as small at $0.1<\rho<0.3$, medium at $0.3<\rho<0.5$, and large at $\rho>0.5$ [20], more recently augmented as very large for $0.5<\rho<0.7$ and extremely large for $\rho \geq 0.9$ [21]. A one-way analysis of variance (ANOVA) compared the $1^{\text {st }}$ tournament week totals with the $2^{\text {nd }}$ tournament week totals, with the $2^{\text {nd }}$ tournament week totals normed to the size of the general $1^{\text {st }}$ tournament week (i.e. 112 matches), subsequent to Kolmogorov-Smirnov tests. Effect sizes [20] were calculated and interpreted as small $(f=0.10)$, medium $(f=0.25)$, and large $(f=0.40)$ to support big data analyses.

The level of significance was set to $p<0.05$. The data in the text and tables are presented as mean percentages.

\section{Ethical approval}

The conducted research is not related to either human or animal use.

\section{Results}

\section{Serve success}

The analyses of service games won showed significant changes from 2002 to 2015 for the total tournament $(\rho=0.90 ; p<0.01), 1^{\text {st }}$ tournament week $(\rho=$ $0.79 ; p<0.01)$, and $2^{\text {nd }}$ tournament week ( $\rho=0.77$; $p<0.01$ ) (Figure 1). A direct comparison revealed significant advantages for the $2^{\text {nd }}$ tournament week totals compared with the $1^{\text {st }}$ tournament week totals $(p<0.01 ; f=0.75)$ (Table 1).

The analyses of points won succeeding $1^{\text {st }}$ serves showed significant changes from 2002 to 2015 for the total tournament $(\rho=0.66 ; p<0.01), 1^{\text {st }}$ tournament week ( $\rho=0.62 ; p<0.05)$, and $2^{\text {nd }}$ tournament week $(\rho=0.56 ; p<0.05)$ (Figure 1). A direct comparison revealed significant advantages for the $2^{\text {nd }}$ tournament week totals compared with the $1^{\text {st }}$ tournament week totals $(p<0.01 ; f=0.61)$ (Table 1$)$.

The analyses of points won succeeding $2^{\text {nd }}$ serves showed significant changes from 2002 to 2015 for the total tournament $(\rho=0.75 ; p<0.01)$ and $1^{\text {st }}$ tournament week $(\rho=0.63 ; p<0.05)$ (Figure 1$)$. A direct comparison revealed significant advantages for the $2^{\text {nd }}$ tournament week totals compared with the $1^{\text {st }}$ tournament week totals $(p<0.05 ; f=0.44)$ (Table 1$)$.

\section{Serve performance}

The analyses of served aces showed significant changes from 2002 to 2015 for the total tournament $(\rho=0.84 ; p<0.01), 1^{\text {st }}$ tournament week $(\rho=0.85$; $p<0.001)$, and $2^{\text {nd }}$ tournament week $(\rho=0.61 ; p<$ 0.05 ), whereas the analyses of served double faults reported significant changes from 2002 to 2015 for the total tournament $(\rho=-0.61 ; p<0.05), 1^{\text {st }}$ tournament week $(\rho=-0.61 ; p<0.05)$, and $2^{\text {nd }}$ tournament week $(\rho=-0.71 ; p<0.01)$ (Figure 1). A direct comparison revealed significant advantages for the $2^{\text {nd }}$ tournament week totals compared with the $1^{\text {st }}$ tournament week totals, with more served aces $(p<0.05$; 


\section{HUMAN MOVEMENT}

R. Grambow, C. O’Shannessy, P. Born, D. Meffert, T. Vogt, Serve efficiency development in tennis

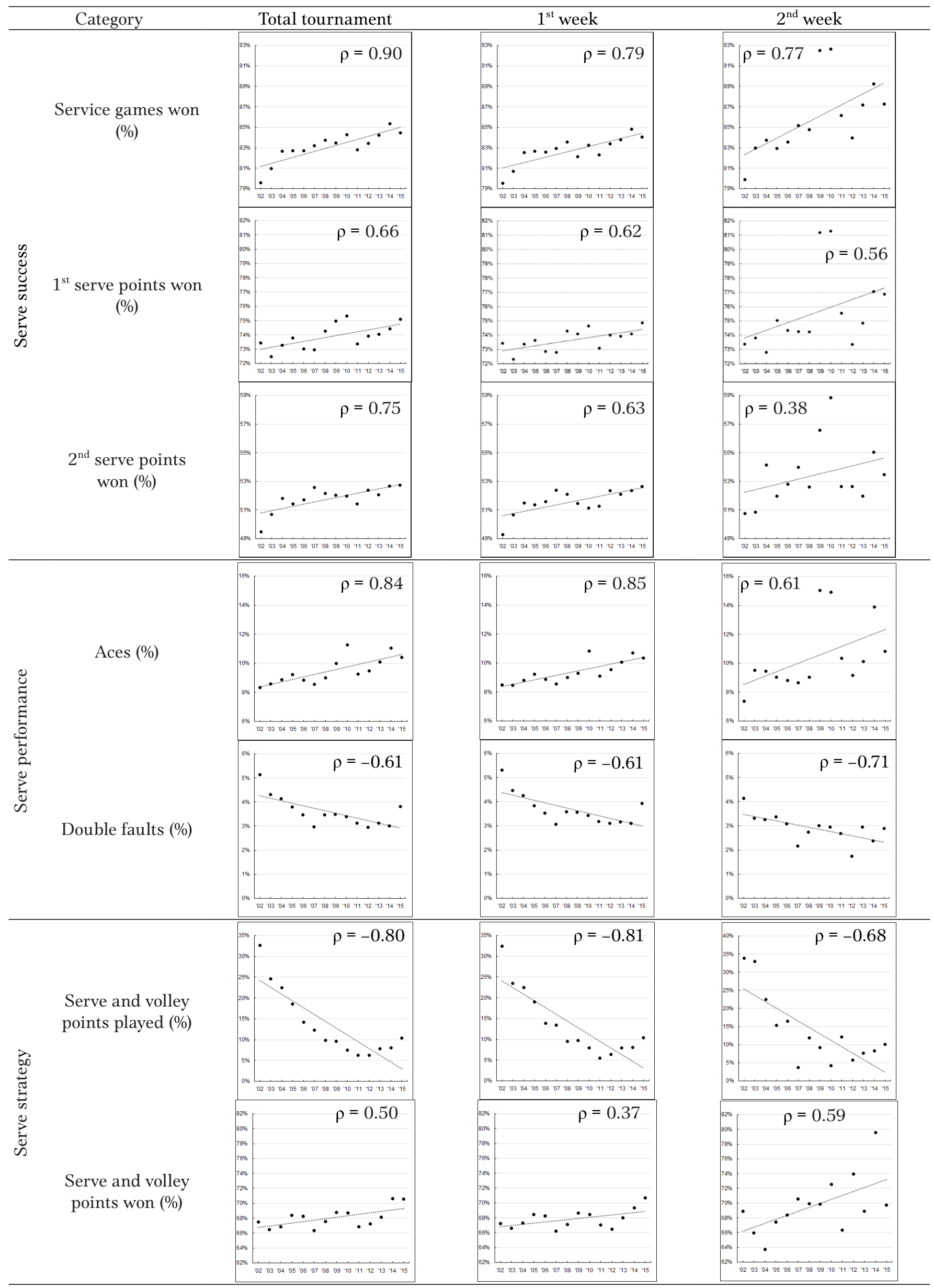


Table 1. Comparison of different tournament weeks

\begin{tabular}{|c|c|c|c|c|c|c|c|c|c|c|c|c|c|c|c|c|}
\hline \multirow{2}{*}{\multicolumn{3}{|c|}{ Category }} & \multicolumn{14}{|c|}{ Tournament year } \\
\hline & & & 2002 & 2003 & 2004 & 2005 & 2006 & 2007 & 2008 & 2009 & 2010 & 2011 & 2012 & 2013 & 2014 & 2015 \\
\hline \multirow{9}{*}{ 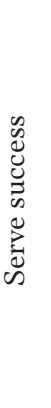 } & \multirow{3}{*}{$\begin{array}{c}\text { Service } \\
\text { games won } \\
(\%)\end{array}$} & & 79.09 & 80.46 & 82.17 & 82.19 & 82.19 & 82.68 & 83.23 & 82.95 & 83.78 & 82.31 & 82.94 & 83.72 & 84.84 & 83.96 \\
\hline & & $1^{\text {st }}$ week & 79.04 & 80.18 & 82.03 & 82.16 & 82.07 & 82.41 & 83.07 & 81.64 & 82.73 & 81.83 & 82.88 & 83.26 & 84.32 & 83.57 \\
\hline & & $2^{\text {nd }}$ week & 79.40 & 82.46 & 83.24 & 82.42 & 83.05 & 84.69 & 84.28 & 91.99 & 92.12 & 85.64 & 83.46 & 86.69 & 88.73 & 86.78 \\
\hline & \multirow{3}{*}{$\begin{array}{l}1^{\text {st }} \text { serve } \\
\text { points won } \\
(\%)\end{array}$} & Total & 73.42 & 72.48 & 73.29 & 73.78 & 73.04 & 72.95 & 74.27 & 74.98 & 75.33 & 73.37 & 73.92 & 74.04 & 74.43 & 75.11 \\
\hline & & $1^{\text {st }} \mathrm{we}$ & 73.43 & 72.29 & 73.35 & 73.62 & 72.85 & 72.78 & 74.28 & 74.09 & 74.63 & 73.07 & 73.99 & 73.92 & 74.08 & 74.86 \\
\hline & & $2^{\text {nd }}$ week & 73.35 & 73.78 & 72.79 & 75.03 & 74.32 & 74.25 & 74.21 & 81.18 & 81.27 & 75.53 & 73.35 & 74.83 & 77.05 & 76.85 \\
\hline & \multirow{3}{*}{$\begin{array}{l}2^{\text {nd }} \text { serve } \\
\text { points won } \\
(\%)\end{array}$} & & 49.49 & 50.68 & 51.81 & 51.43 & 51.73 & 52.57 & 52.17 & 52.02 & 51.96 & 51.42 & 52.37 & 52.08 & 52.66 & 52.75 \\
\hline & & $1^{\text {st }} \mathrm{we}$ & 49.28 & 50.66 & 51.50 & 51.35 & 51.57 & 52.38 & 52.11 & 51.44 & 51.15 & 51.25 & 52.34 & 52.10 & 52. & 52.65 \\
\hline & & $2^{\text {nd }}$ week & 50.75 & 50.86 & 54.14 & 51.96 & 52.81 & 53.98 & 52.60 & 56.56 & 58.85 & 52.64 & 52.64 & 51.96 & 55.04 & 53.47 \\
\hline \multirow{6}{*}{ 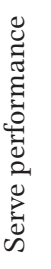 } & \multirow{3}{*}{ Aces (\%) } & & 8.35 & 8.59 & 8.89 & 9.22 & 8.86 & 8.56 & 9.02 & 9.99 & 11.27 & 9.25 & 9.49 & 10.07 & 11.06 & 10.40 \\
\hline & & $1^{\text {st }}$ we & 8.50 & 8.46 & 8.82 & 9.24 & 8.86 & 8.54 & 9.01 & 9.29 & 10.84 & 9.10 & 9.54 & 10.07 & 10.69 & 10.35 \\
\hline & & $2^{\text {nd }}$ week & 7.36 & 9.50 & 9.44 & 9.04 & 8.82 & 8.66 & 9.04 & 15.04 & 14.93 & 10.33 & 9.18 & 10.12 & 13.88 & 10.82 \\
\hline & \multirow{3}{*}{$\begin{array}{c}\text { Double } \\
\text { faults (\%) }\end{array}$} & & 5.14 & 4.32 & 4.13 & 3.79 & 3.47 & 2.96 & 3.47 & 49 & 3.39 & 3.13 & 2.95 & 3.13 & 3.02 & 3.81 \\
\hline & & $1^{\text {st }}$ we & 5.30 & 4.46 & 4.25 & 3.84 & 3.53 & 3.07 & 3.58 & 3.56 & 3.44 & 3.19 & 3.10 & 3.15 & 3.10 & 3.94 \\
\hline & & $2^{\text {nd }}$ week & 4.13 & 3.32 & 3.27 & 3.37 & 3.08 & 2.16 & 2.75 & 3.00 & 2.95 & 2.68 & 1.74 & 2.96 & 2.38 & 2.90 \\
\hline \multirow{6}{*}{ 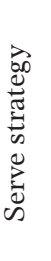 } & \multirow{3}{*}{$\begin{array}{l}\text { Serve and } \\
\text { volley points } \\
\text { played (\%) }\end{array}$} & & 32.60 & 24.63 & 22.44 & 18.59 & 14.22 & 12.29 & 9.87 & 9.66 & 7.51 & 6.29 & 6.31 & 7.86 & 8.04 & 10.35 \\
\hline & & $1^{\text {st }}$ week & 32.39 & 23.45 & 22.43 & 19.03 & 13.90 & 13.45 & 9.55 & 9.73 & 7.93 & 5.48 & 6.38 & 7.91 & 8.01 & 10.40 \\
\hline & & $2^{\text {nd }}$ week & 33.91 & 32.92 & 22.48 & 15.32 & 16.44 & 3.67 & 11.94 & 9.19 & 4.26 & 12.09 & 5.76 & 7.61 & 8.28 & 10.05 \\
\hline & \multirow{3}{*}{$\begin{array}{l}\text { Serve and } \\
\text { volley points } \\
\text { won (\%) }\end{array}$} & & 67.47 & 66.49 & 66.87 & 68.36 & 68.29 & 66.36 & 67.58 & 68.78 & 68.69 & 66.86 & 67.22 & 68.12 & 70.60 & 70.58 \\
\hline & & $1^{\text {st }}$ week & 67.24 & 66.59 & 67.29 & 68.46 & 68.27 & 66.20 & 67.12 & 68.64 & 68.42 & 67.03 & 66.44 & 68.01 & 69.35 & 70.70 \\
\hline & & $2^{\text {nd }}$ week & 68.89 & 65.99 & 63.72 & 67.42 & 68.37 & 70.59 & 69.93 & 69.84 & 72.54 & 66.33 & 73.94 & 68.89 & 79.57 & 69.71 \\
\hline
\end{tabular}

$f=0.40)$ and fewer served double faults $(p<0.05 ; f=$ 0.49 ) for the $2^{\text {nd }}$ tournament week totals (Table 1 ).

\section{Serve strategy}

The analyses of serve and volley points played showed significant changes from 2002 to 2015 for the total tournament $(\rho=-0.80 ; p<0.01), 1^{\text {st }}$ tournament week $(\rho=-0.81 ; p<0.001)$, and $2^{\text {nd }}$ tournament week ( $\rho=-0.68 ; p<0.01$ ), whereas the analyses for serve and volley points won reported only significant changes for the $2^{\text {nd }}$ tournament week $(\rho=0.59 ; p<$ 0.05) (Figure 1). A direct comparison of serve and volley points played and serve and volley points won revealed no significant differences when comparing the $2^{\text {nd }}$ tournament week totals with the $1^{\text {st }}$ tournament week totals (Table 1 ).

\section{Discussion}

The aim of this study was to systematically analyse the development of serving behaviour and serve efficiency in world class men's tennis over a period of 14 years and to find possible differences within the elite men's tennis by directly comparing $1^{\text {st }}$ and $2^{\text {nd }}$ tour- nament week totals of men's Grand Slam tennis. With a particular impact on the $2^{\text {nd }}$ tournament week, the present findings indicate the development of increased serve efficiency in men's world class grass court tennis from 2002 to 2015, since the total tournament results showed significant changes over the years in 6 out of 7 computed parameters, while the $2^{\text {nd }}$ tournament week totals revealed significant advantages in 5 of the 7 recorded parameters in direct comparison with $1^{\text {st }}$ tournament week totals. These results are in line with previous research, suggesting improved serve and return of serve efficiency in modern professional tennis [22].

The present study findings show significantly increased serve success since the percentages for service games won, and $1^{\text {st }}$ and $2^{\text {nd }}$ serve points won increased over the course of time. Simultaneously, serve performance improved, which was underlined by significantly more served aces and fewer served double faults. However, the serve strategy showed significant changes from 2002 to 2015, including decreased serve and volley points played.

Furthermore, the study results present a one-sided difference regarding a direct comparison between $1^{\text {st }}$ and $2^{\text {nd }}$ tournament week totals, including signifi- 
R. Grambow, C. O’Shannessy, P. Born, D. Meffert, T. Vogt, Serve efficiency development in tennis

cant advantages in favour of the $2^{\text {nd }}$ tournament week totals. Not only did the players competing in the $2^{\text {nd }}$ tournament week record a higher serve success by winning their service games and $1^{\text {st }}$ and $2^{\text {nd }}$ serve points at a significantly higher rate; at the same time, their serve performance became better, with serving significantly more aces and significantly fewer double faults. This may be considered surprising because of the higher quality of the competition, meaning the last 16 players in a tournament competing against each other in the $2^{\text {nd }}$ tournament week are supposed not only to serve better but also to return at a higher level. For this reason, the recorded increased serve efficiency by $2^{\text {nd }}$ tournament week totals compared with $1^{\text {st }}$ tournament week totals may be referred to with care.

Since the present findings reveal significantly increased serve success and better serve performance over time, combined with the results of the direct comparison between $1^{\text {st }}$ and $2^{\text {nd }}$ tournament week totals in favour of the players competing in the $2^{\text {nd }}$ tournament week, it seems safe to argue for the importance of serve quality in order to compete for a Grand Slam title like Wimbledon. The study results underline the significance of holding one's own service games in accordance with ongoing competition with better becoming opponents (i.e. closer to the final) and, thus, fewer returning points won. Taking these findings into account, it seems reasonable that a very high serving quality is needed to compete for or win a Grand Slam title, which may be considered in present and future tennis practice contents. These observations confirm previous research, concerning well accepted importance of serve $[4,7,8]$ and the serve (efficiency) being even more important to success at Wimbledon compared with other Grand Slam tournaments [6, 13].

Several findings verify improved serve efficiency, one of them being the perfect serve, an ace. The number of aces hit by the players increased over the investigated time. Cross and Pollard [23] observed increased serve speed in men's singles Grand Slam tennis, a fact that might be a helpful reason for serving aces. Improved serve quality is widely accepted $[3,22$, $24,25]$, but, most interestingly, while the percentage of hitting aces increased, at the same time the percentage of serving a double fault decreased. Therefore, the line of argumentation may not be that the players are willing to take a greater risk on their serve behaviour in order to hit more aces, since a higher risk most reasonably leads to higher double fault percentages. In turn, the opposite seems to be true, since the double fault percentages decreased from 2002 to 2015. Both an increase in aces and a decrease in double faults once more underline a development of higher serve quality in modern male tennis and are in line with previous research [3, 22, 24, 25].

The present study shows another interesting development concerning serve strategy. Over the recorded period, the use of serve and volley as a strategy dropped (i.e., from $33 \%$ in 2002 to $10 \%$ in 2015, with even 6\% in 2011 and 2012). A change of playing style in modern tennis seems obvious [26]; however, and in contrast to commonly established successful playing styles in elite tennis (e.g. baseline tennis over serve and volley), it is difficult to believe that the winning percentages over the investigated time may be the reason. The numbers prove a consistent level of winning around the area of $67-68 \%$. A detailed look at the most recent recorded winning percentages shows an increase over the last years (67\% in 2002 and 2012; 71\% in $2014 / 2015)$. The usage rate dropped every year starting from 2002 (33\%) until $2011(6 \%)$, before the trend reversed slightly up to 2015 (10\%). Even with the slightly reversed trend of usage at the end of the investigated period, it remains questionable if further increasing the usage rate of the serve and volley strategy (10\% in 2015) might be successful, since the winning percentage of $71 \%$ (2014 and 2015) seems to be very promising. For the last 2 recorded years, the findings revealed the same consistent usage rate percentages for the $1^{\text {st }}$ and $2^{\text {nd }}$ tournament week (8\% in 2014; $10 \%$ in 2015), while the winning percentages in the $1^{\text {st }}$ tournament week in 2014 (69\%) and 2015 (71\%) differ compared with the $2^{\text {nd }}$ tournament week in 2014 (80\%) and 2015 (70\%). If one considers these numbers, most notably the $80 \%$ winning percentage of serve and volley during the $2^{\text {nd }}$ tournament week in the 2014 Wimbledon tournament, it seems advisable to implement this game pattern to the service game more often. While it may be questionable if the winning percentages remain high when serve and volley tactics are implemented more often, an increased use of this strategy and its implementation in current and future practice contents may have a considerable impact on succeeding at highest levels. At this point, an investigation of e.g. Roger Federer's winning campaign in 2017 Wimbledon would be very interesting, particularly with the focus on his usage and winning percentages of the serve and volley strategy.

The indicated long-term increased serve efficiency may also be the reason why Wimbledon organizers were forced to implement rule adjustments by introducing the new final set's tiebreak at 12:12 if no winner 
has been found before. The recent 2018 Gentlemen's Wimbledon semi-final featured Kevin Anderson (RSA) defeating JohnIsner(USA) 7:6/6:7/6:7/6:4/26:24 in a $6 \mathrm{~h} 36 \mathrm{~min}$ lasting match, in which both players reached their physical limits owing to their serve performance being so dominant.

\section{Limitations}

Despite careful considerations, this study is subject to limitations. Ideally prospective, randomized trials are needed, but in the case of elite professional tennis players not feasible. The retrospective nature of the study design was the only possible way to analyse and compare such a great amount of complete match data over a period of 14 years. The risk of statistical bias exists (e.g. injury related to serve success, serve performance, serve strategy results, or finally injury dropouts leading to the 59 retirements, as well as the fact that every $2^{\text {nd }}$ tournament week player is also a $1^{\text {st }}$ tournament week player); however, since the study contains every men's match played in Wimbledon between 2002 and 2015 (total matches: $n=1772$ ), the risk may be considered as limited. Furthermore, the analysed data presented by IBM pre-set categories like 'aces,' 'points won on $1^{\text {st }}$ serve,' or 'serve and volley points played'. Although the official category definitions are most reasonable, a non-verifiable preset definition for officially provided data may be considered as limiting itself.

The collected results are not to every extent transferable. The study only includes men's tennis data; therefore, a transfer to women's or junior's tennis may be insufficient. The same applies partly to a transfer to men's tennis on the 2 main surfaces, clay court and hard court, since the collected data include only grass court matches.

\section{Conclusions}

The aim of the present study was to investigate men's serve efficiency via a longitudinal approach to all matches played at Wimbledon in years 2002-2015, while not only focusing on a development over time, but also comparing $1^{\text {st }}$ and $2^{\text {nd }}$ tournament week totals in order to examine possible differences within the world class.

The findings provide long-term evidence for increased service game efficiency, suggesting increased serve success and better serve performance. In detail, service games won, $1^{\text {st }}$ and $2^{\text {nd }}$ serve points won, and ace percentages significantly increased; simultaneously, double fault percentages significantly decreased over the time from 2002 to 2015 in men's singles Wimbledon matches. These results are in line with previous research [3, 22, 24, 25]. Long-term findings also provide a significant decrease of serve and volley points played, while winning percentages remained stable. A direct comparison of $1^{\text {st }}$ and $2^{\text {nd }}$ tournament week totals recorded differences within elite tennis, showing significant advantages in favour of the $2^{\text {nd }}$ tournament week totals. Serve success (service game, $1^{\text {st }}$ and $2^{\text {nd }}$ serve points winning percentages) and serve performance (ace and double fault percentages) turned out more efficient compared with the $1^{\text {st }}$ tournament week totals.

Long-term findings add on previous research [3, $24,25]$ and further prove an increased service game efficiency in elite men's tennis, underlining the importance of transferring these results and, in consequence, implementing the training of these skills into current and future practice contents. The comparison of the $1^{\text {st }}$ and $2^{\text {nd }}$ tournament weeks suggests an even more important role of holding one's own service game on the way to compete and ultimately win a Grand Slam title at Wimbledon.

The present findings might be applicable for all Grand Slam and other ATP tournaments, but need further investigation on the other 3 Grand Slam tournaments, especially because of their different surfaces. All observations may be considered for female tennis; however, since the present study includes exclusively men's tennis, further research is needed on long-term development involving elite female matches.

\section{Acknowledgements}

The authors would like to express their sincere gratitude to Stefan Laux for his support during data analyses. Also, the authors would like to thank the three unknown reviewers for their valuable comments raised during the revision process.

\section{Disclosure statement}

No author has any financial interest or received any financial benefit from this research.

\section{Conflict of interest}

The authors state no conflict of interest.

\section{References}

1. Gillet E, Leroy D, Thouvarecq R, Stein JF. A notational analysis of elite tennis serve and serve-return strategies on slow surface. J Strength Cond Res. 2009;23(2):532539; doi: 10.1519/JSC.0b013e31818efe29. 
R. Grambow, C. O’Shannessy, P. Born, D. Meffert, T. Vogt, Serve efficiency development in tennis

2. Takahashi H, Wada T, Maeda A, Kodama M, Nishizono H, Kurata H. Time analysis of three decades of men's singles at Wimbledon. In: Lees A, Cabello D, Torres G (eds.), Science and racket sports IV. Abinngdon: Routledge; 2008; 239-246.

3. Reid M, McMurtrie D, Crespo M. The relationship between match statistics and top 100 ranking in professional men's tennis. Int J Perform Anal Sport. 2010; 10(2):131-138;doi:10.1080/24748668.2010.11868509.

4. Maquirriain J, Baglione R, Cardey M. Male professional tennis players maintain constant serve speed and accuracy over long matches on grass courts. Eur J Sport Sci.2016;16(7):845-849; doi:10.1080/17461391.2016. 1156163.

5. Elliott B, Saviano N. Serves and returns. In: Roetert P, Groppel J (eds.), World-class tennis technique. Champaign: Human Kinetics; 2001; 207-222.

6. O’Donoghue GP, Brown E. The importance of service in Grand Slam singles tennis. Int J Perform Anal Sport. 2008;8(3):70-78;doi:10.1080/24748668.2008.11868449.

7. Ma SM, Liu CC, Tan Y, Ma SC. Winning matches in Grand Slam men's singles: an analysis of player performance-related variables from 1991 to 2008. J Sports Sci. 2013;31(11):1147-1155; doi: 10.1080/02640414. 2013.775472.

8. Meffert D, O’Shannessy C, Born P, Grambow R, Vogt T. Tennis serve performances at break points: approaching practice patterns for coaching. Eur J Sport Sci. 2018: 18(8):1151-1157; doi: 10.1080/17461391.2018.1490821.

9. O'Donoghue P, Ingram B. A notational analysis of elite tennis strategy. J Sports Sci. 2001;19(2):107-115; doi: 10.1080/026404101300036299.

10. Del Corral J, Prieto-Rodríguez J. Are differences in ranks good predictors for Grand Slam tennis matches? Int J Forecast. 2010;26(3):551-563; doi: 10.1016/j.ijforecast.2009.12.006.

11. Weber K, Exler T, Marx A, Pley C, Röbbel S, Schäffkes C. Faster serves, shorter rallies and higher time pressure for basic strokes in the tennis world's best [in German]. Leistungssport. 2010;40(5):36-42.

12. Weber K, Born P. The special importance of the extended opening of the game in competitive tennis [in German]. Leistungssport. 2012;42(6):26-32.

13. Knight G, O’Donoghue P. The probability of winning break points in Grand Slam men's singles tennis. Eur J Sport Sci. 2012;12(6):462-468; doi: 10.1080/17461391. 2011.577239.

14. Hughes M, Clarke S. Surface effect on elite tennis strategy. In: Reilly T, Hughes M, Lees A (eds.), Science and Racket Sports. Abingdon: Taylor \& Francis; 1995; 272-277.

15. Dindar MD, Toksöz İ, Taşkın C, Uluçam E. Analysis of the serves in the men's semi-final and final competitions of Wimbledon tennis tournament. Sport Sci. 2011; 6(3):185-192.

16. Reid M, Morgan S, Whiteside D. Matchplay characteristics of Grand Slam tennis: implications for train- ing and conditioning. J Sports Sci. 2016;34(19):17911798; doi: 10.1080/02640414.2016.1139161.

17. Nowak M, Panfil R. Scoring abilities in the game of tennis - a pragmatic study of unique cases. Hum Mov. 2012; 13(4):313-322; doi: 10.2478/v10038-012-0036-z.

18. Ferrauti A, Bastiaens K. Short-term effects of light and heavy load interventions on service velocity and precision in elite young tennis players. Brit J Sports Med. 2007;41(11):750-753; doi: 10.1136/bjsm.2007.036855.

19. Hernández-Davo H, Urbán T, Sarabia JM, Juan-Recio C, Moreno FJ. Variable training: effects on velocity and accuracy in the tennis serve. J Sports Sci. 2014; 32(14):1383-1388; doi: 10.1080/02640414.2014.891290.

20. Cohen J. A power primer. Psychol Bull. 1992;112(1): 155-159; doi: 10.1037//0033-2909.112.1.155.

21. Hopkins WG, Marshall SW, Batterham AM, Hanin J. Progressive statistics for studies in sports medicine and exercise science. Med Sci Sports Exerc. 2009;41(1): 3-13; doi: 10.1249/MSS.0b013e31818cb278.

22. Filipcic A, Zecic M, Reid M, Crespo M, Panjan A, Nejc S. Differences in performance indicators of elite tennis players in the period 1991-2010. J Phys Educ Sport. 2015;15(4):671-677; doi: 10.7752/jpes.2015.04102.

23. Cross R, Pollard G. Grand Slam men's singles tennis 1991-2009. Serve speeds and other related data. Coach Sport Sci Rev. 2009;16(49):8-10.

24. Barnett T, Meyer D, Pollard G. Applying match statistics to increase serving performance. Med Sci Tennis. 2008;13(2):24-27.

25. Barnett T, Pollard G. How the tennis court surface affects player performance and injuries. Med Sci Tennis. 2007;12(1):34-37.

26. Schönborn R. Optimal tennis training - the path to successful tennis from novices to world class [in German]. Balingen: Spitta; 2010. 